\title{
A SURVEY ON AUTOMATIC ATTENDANCE SYSTEM ALONG WITH TEMPERATURE USING IOT
}

\author{
Rohini M \\ Assistant Professor \\ Department of CSE \\ Coimbatore Institute of Engg and Tech \\ Coimbatore \\ Tamil Nadu \\ Kamali S \\ Student \\ Department of CSE \\ Coimbatore Institute of Engg and Tech \\ Coimbatore \\ Tamil Nadu \\ Nitheesh M \\ Student \\ Department of CSE \\ Coimbatore Institute of Engg and Tech \\ Coimbatore \\ Tamil Nadu
}

\begin{abstract}
Automatic attendance methods are very helpful for students and workers in order to make use of their time more effectively. Maintaining attendance is the most troublesome assignment in different organizations. In recent days we have seen abrupt increment in the utilization of biometric technology in the fields of IT, education institute, transportation, etc. Internet of things is also blooming parallel. Automatic attendance system is an implementation of internet of things through Arduino ide, thingspeak finger print scanner $\mathrm{R} 305$ in order to reduce the time consumed by the traditional attendance method. There are various technologies like RFID, fingerprint and face recognition technologies are introduced in order to save time and reduce efforts. In this paper we are going to compare those technologies and understand which is best among them.
\end{abstract}

\section{INTRODUCTION}

Attendance is the concept of people, individually or as a group, appearing at a location for a previously scheduled event. Measuring attendance is a significant concern for many organizations, which

\author{
Meganathan K \\ Student \\ Department of CSE \\ Coimbatore Institute of Engg and Tech \\ Coimbatore \\ Tamil Nadu \\ Yuvan Shankar S \\ Student \\ Department of CSE \\ Coimbatore Institute of Engg and Tech \\ Coimbatore \\ Tamil Nadu \\ Deepa N R \\ Assistant Professor \\ Department of CSE \\ Coimbatore Institute of Engg and Tech \\ Coimbatore \\ Tamil Nadu
}

can use such information to gauge the effectiveness of their efforts and to plan for future efforts.

Since olden days, the method of recording attendance is always manual. Even though this develops the student-teacher relationship and binds them together, it is time consuming and prone to human errors. This also becomes stressful at times. In order to make it error free and reduce the wastage of time, it is necessary to implement Automatic Attendance Management System thus making it more efficient and effective.

\section{INTERNET Of THINGS}

The Internet of Things (IoT) is a system of interrelated computing devices, mechanical and digital machines, objects, animals or people that are provided with unique identifiers and the ability to transfer data over a network without requiring human-to-human or human-to-computer interaction. Internet of Things (IoT) is the networking of physical objects that contain electronics embedded within their architecture in order to communicate and sense interactions amongst each other or with respect to the external environment. In the upcoming years, IoT-based technology will offer 
advanced levels of services and practically change the way people lead their daily lives. Advancements in medicine, power, gene therapies, agriculture, smart cities, and smart homes are just a very few of the categorical examples where IoT is strongly established.

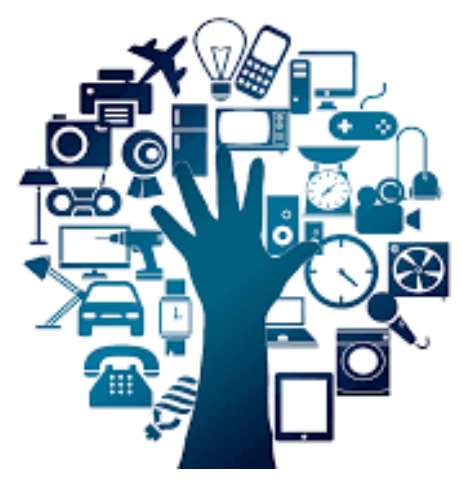

Figure 1 : Internet of Things

\section{MANUAL ATTENDANCE}

Attendance is a most important of a students life. Students' attendance is one of the fundamental responsibility of the institution. Attendance also helps to build familiarity between students and teachers. In many education institution and organization attendance plays an important role. When the student is regular to class and having a good attendance will always have a very good chance of learning more. Keeping track of attendance will help us in many ways like record keeping, assessment of students and consistent attendance in class. This traditional method of taking attendance requires the teachers or staff to fill in the attendance sheet by calling out the student's name. With manual system information are often has to be written down and copied more than once. When we manually do a task there is a chance of making an error without our knowledge. And it will also consumes a lot of time. When the attendance is taking in a traditional way which makes the teachers to be the attendance record keeper of the students, which eats the precious time of teaching and the energy of the class. Not only educational institution but also some business and in healthcare centers also uses the way of taking attendance manually. The process of taking attendance in traditional way has been in practice for a long and still in many institution it has been following the traditional method. This process always have been in the form of hardcopy papers and the documentations were manually done.

When the attendance are taken manually we are being pushed to be perfect. With the chance of getting proxy so easily there is a need to double checking each and everything. In case of a lot of students it will take away a lot of time and energy and also it will be a burden for the teachers and staffs. When attendance are taken manually there is always a chance of making some errors like marking absent to a wrong person or accidentally switching data or inconsistency in data, duplication in data.

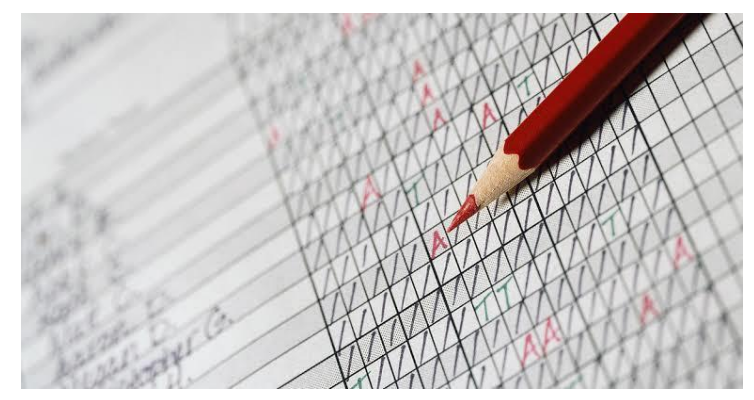

Fig 2: Manual attendance

When it comes to attendance, the number of students who are absent is also as important as students who are present in the class. But still the task of the recording and reporting the absentees fall on teachers. As this method uses paper to mark the attendance there is always a thread of missing or any damage made to the attendance sheet. There is always a lack of security in this method. This method put too much of paperwork on teachers. When a mistake is made while entering the attendance, in order to correct the mistake it has to be redone completely rather than just updating it. It taken lot of energy and physical space to keep track of the attendance document, to find information and to keep details secure. Even though it doesn't require any hardware or software to store or maintain data but doing it manually is really a hard task to manage it. As the name suggested, this system completely dependent on every individuals.

\section{RFID ATTENDANCE}

Radio frequency identification (RFID) is the wireless non-contact use of radio frequency waves to transfer data. Tagging items with RFID tags allows users to automatically and uniquely identify and track inventory and assets. Radio-frequency identification (RFID).Radio-frequency

identification (RFID) uses electromagnetic fields to automatically identify and track tags attached to objects. An RFID system consists of a tiny radio transponder, a radio receiver and transmitter RFID tags are used in many industries most educational institution's administrators are concerned about student irregular attendance. 


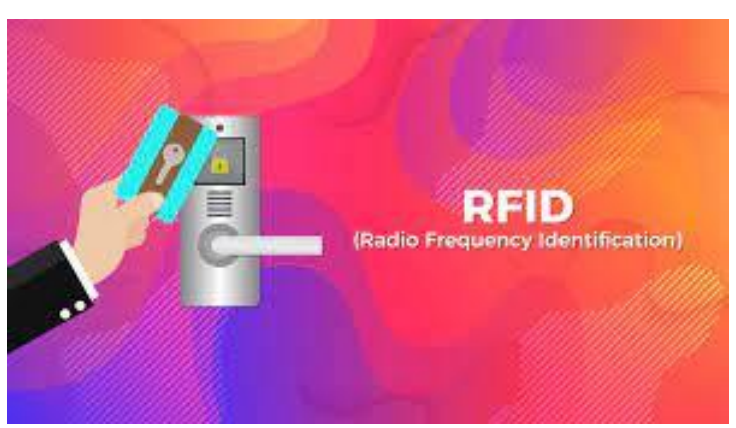

Fig 3: Radio Frequency Identification

Truancies can affect student overall academic performance. The conventional method of taking attendance by calling names or signing on paper is very time consuming and insecure, hence inefficient. Radio Frequency Identification (RFID) based attendance system is one of the solutions to address this problem. This system can be used to take attendance for student in school, college, and university. It also can be used to take attendance for workers in working places. Its ability to uniquely identify each person based on their RFID tag type of ID card make the process of taking the attendance easier, faster and secure as compared to conventional method. . With real time clock capability of the system, attendance taken will be more accurate since the time for the attendance taken will be recorded. The system can be connected to the computer through RS232 or Universal Serial Bus (USB) port and store the attendance taken inside database. A prototype of the system has been successfully fabricated in author's proposed different view for attendance management system. However, checking more than 70 students based on their iris pattern is time consuming, and mainly expensive, and for universities this is not the best choice. Systems based on iris recognition are used in many areas, such as access control for high security installations, credit card usage verification, and employee identification. Such as access control for high security installations, credit card usage verification, and employee identification The RFID tag was very useful for all students and colleges, work places. It is very useful for all the industry. It was too helpful fast to technology. They used real time face detection algorithms integrated on an existing Learning Management System (LMS), which automatically detects and registers student attending on a lecture. They designed and implemented wireless recognition. The attendance easier, faster and secure as compared to conventional method.

\section{FINGERPRINT ATTENDANCE}

It is well known fact that every human being are born with a different pattern on their finger. These features are used to identify and differentiate pattern on their fingers and these features are used to identify and differentiate between two different persons. Fingerprint attendance system has been developed to automate the method of taking attendance. Fingerprint is one of the oldest biometric technology. It have been used for identification over many years. This technology have a great impact on educational organization or institution. This system is not only used in educational institution but also in many other places like IT, hospital and so on. The fingerprint technology has been in practice since nineteenth century when Sir Francis Galton defined some of the points or characteristics from which fingerprint can be identified. These "Galton points" are the foundation for the science of fingerprint identification. A subset of the Galton points referred to as minutiae has been utilized to develop automated fingerprint technology. Fingerprint scanner have become very helpful in terms of technology and scanner used in scanning. The very basic process of a fingerprint scanner is to form and match the pattern inside the scanner. To set the fingerprint scanner first we need to scan the fingerprint of every person and store the data so that when we place our finger in the scanner it can match and verify our presence in the class. The fingerprint recognition and verification technology has been adopted in order to save time and eliminate the errors.

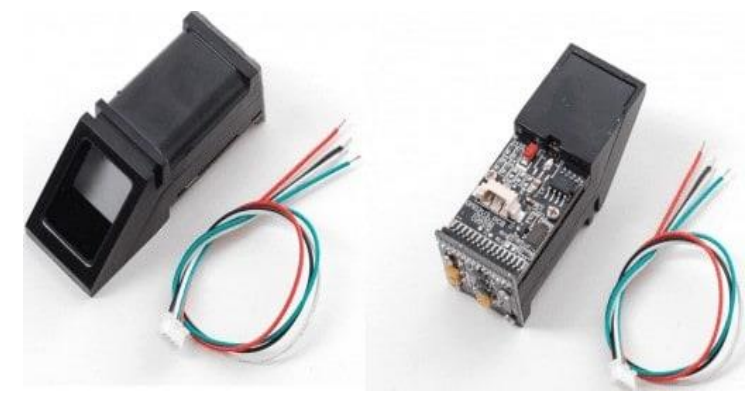

Fig 4: Fingerprint scanner

A fingerprint detecting device need to be placed in classroom so that when a student swipes a finger across the scanner, a check could be carried out for the students. The device reads the fingerprint pattern and verify with the data that have been already stored. If the details present in the database is matched then the student will be marked as present. If it doesn't match then the student is marked as absent. With the use of this technology is not a difficult task to record absentees in the class even in the class with a large number of students. Fingerprint attendance is completely safe, for that it is unique as well as reliable. When the data are stored directly in system, it eliminates the risk of missing of data and duplication in data or any other careless mistake. The two main category of fingerprint scanner technology are minutiae-based 


\section{International Journal of Engineering Applied Sciences and Technology, 2021 \\ Vol. 6, Issue 5, ISSN No. 2455-2143, Pages 131-135 \\ Published Online September 2021 in IJEAST (http://www.ijeast.com)}

matching and pattern matching. Pattern matching will simply compare two images to see how similar they are and used to detect duplicates. Minutiaebased matching is used widely in recognition technology, it relies on the minutiae points specifically the location and direction of each points. When we use this system the results are highly accurate. It is easy to use and will not require more manpower to store and maintain data. This system only takes a small amount of storage space. There are four types of fingerprint scanner present such as optimal scanner, capacitive or CMOS scanner, ultrasound fingerprint scanner and thermal scanner. When the educational institution have more number of class the cost of implementation might get high. Once when we set the input data to compare it cannot be changed later.

\section{FACE RECOGINITION}

With the advancement of technologies each and every day, humanity is slowly going towards contactless everything. Face recognition system is very useful in life applications especially in security control systems. The airport protection system uses face recognition to identify suspects and FBI (Federal Bureau of Investigation) uses face recognition for criminal investigations. It is quite evident that the future ahead of us will become so much advance that maybe $90 \%+$ things that we are doing right now will be either automated or become contactless. One such advancement will be the facial recognition technology or the FR tech, which is the prime focus of this article. Face recognition technology is a system to verify the identity of a person from analyzing an image footage it is very easy to verify the identity of the person. It was very quick and easier.

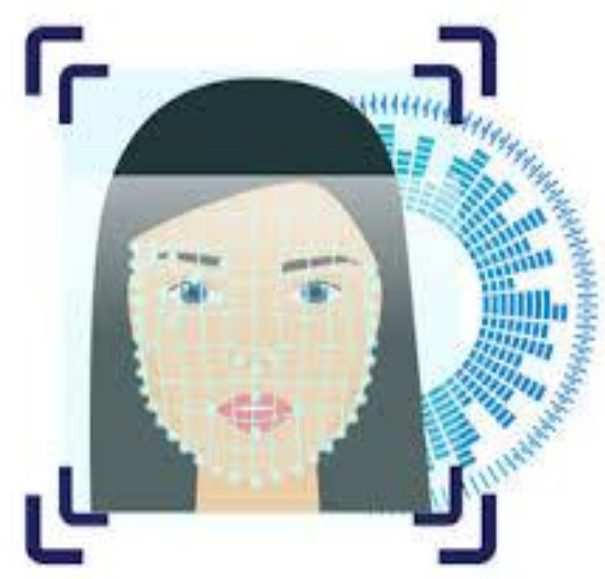

Fig 5 : Face recognition

The advantages of this system that it would take a long article to note down each and every one of them. Attendance system is very important in schools and colleges' Manual attendance system has many difficulties like it may less accurate and critical to maintain. So, attendance system using face recognition technique increase the accuracy and also it required less time than other methods. There are many existing system for attendance such as face recognition using IOT, PIR sensors and so on. So, attendance system using face recognition technique increase the accuracy and also it required less time than other methods. The median filtering is applied to remove noise followed by conversion of color images to grayscale images. After that, contrastlimited adaptive histogram equalization (CLAHE) is implemented on images to enhance the contrast of images. The facial images are then classified and recognized based on the best result obtained from the combination of algorithm, enhanced LBP and PCA. For face detection and face recognition the raspberry pi. If the camera is connected to Raspberry pi USB port then only images will capture of the students who are available in the class for face detection. The student who is not registered will also be able to register on the spot and notification will be given if students sign in more than once. The average accuracy of recognition is $100 \%$ for good quality images, $94.12 \%$ of low-quality images and $95.76 \%$ for Yale face database when two images per person are trained. But today, our prime focus will be on one of the many applications of facial recognition technology, and that is using face recognition based attendance system.

\section{COMPARISON OF ATTENDANCE TECHNOLOGIES}

Cost: cost is one of the major factor we notice in everything every day. When we compare all the attendance technologies that is being used, manual attendance method requires less cost when compared to all the other technologies.

Time: In this modern world we all prefer something that consumes less of our time. In this attendance technologies we have fingerprint technology, face recognition and RFID technology which consumes very less time where manual attendance method consumes a lot of our time

Easy to use: It is common that people hate complication and we all prefer something easy. By looking at all the attendance technology manual attendance system seems to be somewhat easy to use where we just need a paper and pen to mark attendance while on the other hand the remaining technologies require computers and some specific software to run the technology where it gets hard to use sometime.

Security: As we are dealing with data of many people it is our responsibility to secure the data of the people. In the fingerprint and face recognition 
technologies we use the unique feature of people which gives us the high level of security meanwhile in RFID we have the possibility of misusing the RFID tag or getting a proxy and in manual attendance system we have chance of missing the document or getting a careless mistake which leaves us with low level of security.

Maintaining data: Maintaining data comes handy in many occasions. In, among the different attendance technologies like RFID, fingerprint and face recognition technologies its it easier to maintain data where we let the computer system to work for us and it makes maintaining data a easy job but in manual attendance system we have to do all the job by our self which makes it hard to maintain data.

\section{CONCLUSION}

The attendance system is developed by many technologies. Some of them are manually taking attendance by calling out student's name, by using RFID tag and reader, fingerprint recognition, face recognition. Each technology meet our needs in different ways. But also having drawbacks. After getting to learn about every technologies used to take attendance and analyzing the pros and cons of each technology we can conclude the face recognition has the efficiency to meet all our needs and best among the existing attendance system. Face recognition system identify the individuals by comparing their input image obtained from recording video frame with respect to train image. In this way we can completely avoid proxy in attendance or making error while entering the data. And also saves our time.

\section{REFERENCE}

[1] wang, D., Fu, R.,\& Luo, Z.(2017). Classroom attendance auto-management based on deep learning.

[2] Walia, H., \& Jain, N. (2016). Fingerprint Based Attendance Systems-A Review. International Research Journal of Engineering and Technology (IRJET) Volume, 3.

[3] Nath, A., \& Mukhopadhyay, A. (2017). A Novel Student Attendance Tracking System Using Android Mobile Phone.

[4] Karwan Jacksi, Falah Ibrahim, Shahab Ali, "Student Attendance Management System", University of Zakho, Iraq, 2018.

[5] Lia kamelia, Eki Ahmad Dzaki Hamidi,Afit Nugraha, Real-time online attendance system based on fingerprint and GPS in the smartphone,978-15386-6162-5/18/2018 IEEE.
[6] Mesquita, Joao \& Guimaraes, Diana \& Pereira, Carlos \& Santos, Frederico \& Almeida, "Assessing the ESP8266 WiFi module for the Internet of Things", IEEE, 2018.

[7] Colin Dow, "Internet of Things Programming Projects: Build modern IOT with the Raspberry Pi 3 and Python", $\mathrm{Pa}$

[8] Pranava Madan, Lakshay Dhama, Rajiv Dahiya , Ruchika Doda, " A Review Paper on Arduino Research Papers", International Journal for Research in Applied Science \& Engineering Technology (IJRASET), March,2019.

[9] Pradeeka Seneviratne, "Hands-On Internet of Things with Blynk: Build on the power of Blynk to configure smart devices and build exciting IOT projects", Paperback, May 28,2018, Packt Publish

[10] Karwan Jacksi, Falah Ibrahim, Shahab Ali, "Student Attendance Management System", University of Zakho, Iraq, 2018. 